\title{
Closing in on the perfect Fontan
}

\author{
Harold M. Burkhart, MD
}

See related article on pages 2517-24.

Since the introduction of the Fontan operation more than 4 decades ago, many modifications to the operation have occurred and have been debated in the name of finding the "perfect" Fontan. Along the way, the "Ten Commandments" for a Fontan have been reduced to 4 or 5 . Valves have been repaired, subaortic and aortic arch obstructions have been relieved, and pulmonary architecture has been altered, all in hopes of producing a perfect Fontan circulation. Although progress has certainly been made with the surgical modifications, controversy still exists. Extracardiac or lateral tunnel, fenestration or no fenestration, beating heart or cardiac arrest, and even on-pump or off-pump are just of few of the issues currently debated. The one thing in common with regard to these controversies is that excellent surgical results can be expected in the current era.

Dabal and colleagues ${ }^{1}$ present a 2-decade review of their experience with 207 Fontan procedures performed with an internal or, more recently, external polytetrafluoroethylene conduit. The patient group was a complex group. Tricuspid atresia and double-inlet left ventricle accounted for $42 \%$, whereas hypoplastic left heart syndrome accounted for only $9 \%$ because representation of these cases was limited to the last decade of the study period. Early mortality was excellent, decreasing from $7 \%$ in the earlier era to $0 \%$ in the last 6 years of the review. With robust long-term follow-up, the survival was noted to be $77 \%$ at 20 years. Importantly and uniquely, during this period no late phase of increasing risk was identified. Furthermore, freedom from any reoperation, including transplant, was greater than $90 \%$ at 20 years. Dabal and colleagues ${ }^{1}$ should be congratulated on their surgical results in constructing a "perfect" Fontan pathway that has provided excellent palliation in the first 1 to 2 decades.

One area in which the review falls short is in the discussion of their Fontan procedure exclusion criteria.
Admittedly, given the retrospective nature and the fact that likely several surgeons have been involved, this is a formidable request. As we look to closing in on the perfect Fontan pathway, however, it would be helpful to know how much atrioventricular regurgitation is too much, what ventricular function is good enough, and just how small the pulmonary arteries can be. Although these issues affect all Fontan candidates, they are no more readily apparent than in the patients with hypoplastic left heart syndrome. In a time when the expectation from medical colleagues and families is to progress to a Fontan operation, further studies from this group as well as others need to focus on defining these exclusion criteria.

Finally, it bears keeping in mind that the story with a perfect Fontan pathway does not end at 20 years. Clearly, the Fontan reconstruction has given palliation and survival to a complex group of patients who, before the operation, had few options. It is important to remember the spirit in which the operation was developed and intended. At 20 and 30 years after the Fontan operation, we are becoming increasingly aware of the drawbacks of this approach. Elevated central venous pressure and lower cardiac output do not appear to be tolerated for a long period in many patients, with liver disease and protein-losing enteropathy becoming more prevalent. Although a perfect Fontan pathway is a key step to the care of these difficult patients, it is just part of the ultimate solution. Certainly patient selection is critical, with some better served with a pulsatile Glenn shunt. For those who do go on to Fontan operation, research focusing on stem cell therapy, mechanical assist devices, and medical therapy such as pulmonary dilators may provide the next step.

\section{Reference}

1. Dabal RJ, Kirklin JK, Kukreja M, Brown RN, Cleveland DC, Eddins MC, Lau Y The modern Fontan operation shows no increase in mortality out to 20 years: A new paradigm. J Thorac Cardiovasc Surg. 2014;148:2517-24.

\footnotetext{
From the Division of Cardiovascular and Thoracic Surgery, Children's Hospital of Oklahoma, University of Oklahoma Health Sciences Center, Oklahoma City, Okla. Disclosures: Author has nothing to disclose with regard to commercial support. Received for publication Oct 12, 2014; accepted for publication Oct 14, 2014.

Address for reprints: Harold M. Burkhart, MD, Division of Cardiovascular and Thoracic Surgery, Children's Hospital of Oklahoma, University of Oklahoma Health Sciences Center, PO Box 26901, WP-2230, Oklahoma City, OK 73105 (E-mail: Harold-burkhart@ouhsc.edu).

J Thorac Cardiovasc Surg 2014;148:2525

$0022-5223 / \$ 36.00$

Copyright (c) 2014 by The American Association for Thoracic Surgery

http://dx.doi.org/10.1016/j.jtcvs.2014.10.072
} 